\title{
What Do the 'Breadwinners' Do? Understanding Fathers' Roles in Family Food Work in Australia
}

\author{
Lillian Fenner ${ }^{1} \&$ Cathy Banwell ${ }^{1}$ \\ ${ }^{1}$ National Centre for Epidemiology and Population Health, Research School of Population Health, The Australian \\ National University, Australia \\ Correspondence: Cathy Banwell, National Centre for Epidemiology and Population Health, Research School of \\ Population Health, The Australian National University, Australian Capital Territory 2614, Australia. Tel: 61-2- \\ 6125-0016. E-mail: cathy.banwell@anu.edu.au
}

\author{
Received: December 30, 2018 Accepted: January 22, 2019 Online Published: January 30, 2019 \\ doi:10.5539/gjhs.v11n3p1 URL: https://doi.org/10.5539/gjhs.v11n3p1
}

\begin{abstract}
In the context of global concern about children's weight and health, this study aims to investigate the extent to which Australian fathers are involved in family food work which includes feeding the family, and associated tasks such as shopping, food selection, planning meals, preparing, cooking, and cleaning up. It seeks to identify whether fathers consider children's 'healthiness' and weight gain when performing these tasks, and what, if any, nutritional information resources they accessed.

A qualitative exploratory study using semi-structured face-to-face interviews was conducted with eight fathers aged between 25 to 50 years living in the Australian Capital Territory. Participants discussed their roles in food provisioning and their perceptions of the food work process.

A commitment to equally sharing domestic tasks between partners was frequently acknowledged amongst participants, despite the persistence of performative gendered norms. Male participants also discussed some of the constraining factors influencing their involvement in food provisioning. These included time scarcity, working commitments and cost. Whilst nutrition was considered when selecting and preparing food, most participants reported that they had not accessed or received nutritional and health information for their children. These findings provided insights into fathers' perceptions of their roles and responsibilities of healthy food provisioning. Furthermore, this study suggests that public health researchers and health promoters should adapt their efforts to include fathers in education about the nutritional content of food for primary aged children, given the apparent paucity in these resources.
\end{abstract}

Keywords: father and paternal, family, food work, food provisioning, child nutrition, perception, gender role

\section{Introduction}

As concern over Australian children's increasing weight and potential to develop diet-related chronic diseases has grown, there has been mounting interest in the nutritional quality and content of children's diets (Khandpur, Charles, \& Davison, 2016; Tanner et al., 2013). The family is commonly viewed as a critical site for early intervention and prevention of childhood obesity, as children often develop their food habits within the family setting (Tanner et al., 2013). As a result, the roles and responsibilities of parents in relation to healthy food provisioning are being increasingly scrutinised (Tanner et al., 2013). Research on children's nutrition has intensely focused women's role as the 'default parent' and primary determinant of the family diet (Bava, Jaeger, \& Park, 2008; Owen et al., 2010; Slater, Sevenhuysen, Edginton, \& O'Neil, 2012; Tanner et al., 2013). There is a paucity of research addressing fathers' roles in the provision of the children's diets, and fathers have been found to be under-represented on child feeding research (Khandpur, Blaine, Fisher, \& Davison, 2014).

Men have always had a role in food provisioning (Vollmer, Adamsons, Foster, \& Mobley, 2015) fulfilling the traditional gender stereotype as the 'breadwinner' providing financial support, whilst mothers are generally portrayed as the 'caretaker', who feeds the family (Vollmer et al., 2015). The concept of a gendered 'ethics of care' highlights the gendered dynamics of food work (Schubert, 2009; Gilligan, 1982). However, these gender stereotypes are being challenged in the modern and post-modern era, as women in countries such as Australia, have moved into paid employment, generating some reorganisation of what were once considered traditional 
family caring duties (Mallan et al., 2014; Tanner, Petersen, \& Fraser, 2013). As this suggests, domestic family practices are also impacted by employment conditions and income. Whilst male partners in dual income households are becoming more involved in domestic duties, they often continue to be employed in full-time positions (Mallan, 2013; Mallan et al., 2014; Owen, Metcalfe, Dryden, \& Shipton, 2010; Tanner et al., 2013). In Australia, mothers choose part-time work as a strategy for managing domestic and caring tasks (Owen et al., 2010; Tanner et al., 2013).

Nevertheless, due to evolving societal norms and expectations, men are now expected to be more involved in domestic and caring duties. Indeed, Australian families appear to be transitioning with more than half of fathers acknowledging that they had a role in organising meals, determining food proportions, and in deciding if their child eats the right food (Mallan et al., 2014). However, there has been minimal policy or research interest in men's influence on children's dietary health (Tanner et al., 2013). Almost all respondents (98\%) in four recent studies of family food practices were mothers (Russell, Haszard, Taylor, Heath, Taylor, Campbell, Campbell, 018). Little is known about fathers' views and practices in relation to the provision of healthy food for families, and more specifically children (Fouts \& Brookshire, 2009; Mallan, 2013). As fathers begin to play a greater role in food provisioning, there is a need to gain better understanding of their knowledge, attitudes and practices in providing children healthy food (Tanner et al., 2013). In this paper, the term 'family food provisioning' or 'food work' includes the choice, purchase, planning, preparation, cooking and consumption of family food.

This qualitative study aims to address this lack of research by exploring: the fathers practices, attitudes and perceptions towards healthy family food provisioning; and the considerations and constraints, such as time and work pressures that influence fathers' attitudes and practices in relation to parenting and food provisioning. Finally, we sought to understand fathers' attitudes and considerations towards the importance of providing healthy family food to children, and what, if any, nutritional resources they access. Gaining insight into fathers' perceptions of their roles and responsibilities towards healthy food provisioning will assist public health researchers and health promoters tailor their efforts to educate fathers and families about the nutritional content of food and will go a small way to address gendered research blindness to men's roles in family food work.

\section{Methods}

\subsection{Design}

This qualitative study took an exploratory interpretive approach in order to build understanding of an underresearched area. As with all qualitative research methods, an interpretivist paradigm relies on textual data and employs meaning-based rather than statistical forms of data analysis. Interpretive methodologies place the meaning-making practices at the centre of scientific explanation and aims to produce a holistic understanding of rich, contextual, and generally unstructured, data through dialogue between researchers and participants in a natural setting (Ponelis, 2015). Given the defining feature of this study is its focus on 'how' and 'why' questions, this approach was appropriate to address the descriptive and exploratory nature of this research question. The interpretivist research paradigm enabled open and exploratory questions to be asked, and assisted in gaining deeper insights into fathers' experiences of family food provisioning.

\subsection{Participants}

A purposive, snowballing recruitment process involved the lead author emailing personal contacts and asking them to alert potential participants to the study. The key eligibility criteria for inclusion in the study required the male participant to (a) have a child aged between five and 12 years old and (b) have regular and shared responsibility for caring for their child/ren. Fathers of primary school aged children were selected as the target, as children of this age are often more willing to eat a wider variety of foods (Standord Children's Health, 2017) and increasingly take control over their food choices. This allowed us to consider whether fathers were able to balance their children's potentially unhealthy food preferences with considerations of healthiness. Additionally, fathers had to have a minimum of $50 \%$ shared care for their child or children. While, this may be a greater time commitment than many Australian fathers give, it allowed us to explore practices toward food provisioning of fathers who had some involvement in providing regular care for their child or children. Once, they agreed to participate, participants were emailed with a participant information sheet attached and interview dates and times were organised at the convenience of each participant. 
Table 1. Participant's sociodemographic information

\begin{tabular}{|c|c|c|c|c|c|c|c|c|}
\hline Pseudonym & Age & $\begin{array}{l}\text { No. of } \\
\text { children }\end{array}$ & $\begin{array}{l}\text { Marital } \\
\text { status }\end{array}$ & $\begin{array}{l}\text { Highest } \\
\text { education } \\
\text { qualification }\end{array}$ & Occupation & $\begin{array}{l}\text { Income } \\
\text { level }\end{array}$ & $\begin{array}{l}\text { Employment } \\
\text { status }\end{array}$ & $\begin{array}{l}\text { Partner's } \\
\text { employment } \\
\text { status }\end{array}$ \\
\hline Adam & 50 & 2 & Married & $\mathrm{PhD}$ & $\begin{array}{l}\text { IT Policy } \\
\text { analyst }\end{array}$ & $\begin{array}{l}\$ 87,000- \\
\$ 180,00\end{array}$ & Full-time & Full-time \\
\hline Benjamin & 33 & 2 & Married & Diploma & Policeman & $\begin{array}{l}\$ 87,000- \\
\$ 180,000\end{array}$ & Full-time & Full-time \\
\hline Caleb & 44 & 2 & Married & $\begin{array}{l}\text { Bachelor } \\
\text { (hons) }\end{array}$ & $\begin{array}{l}\text { Software } \\
\text { engineer }\end{array}$ & $\begin{array}{l}\$ 87,000- \\
\$ 180,000\end{array}$ & Full-time & Part-time \\
\hline Daniel & 40 & 2 & Separated & Bachelor & IT manager & $\begin{array}{l}\$ 87,000- \\
\$ 180,000\end{array}$ & Full-time & $\begin{array}{l}\text { Four days per } \\
\text { week }\end{array}$ \\
\hline Ethan & $\begin{array}{l}\text { Not } \\
\text { disclosed }\end{array}$ & 1 & Married & Postgraduate & Legal officer & $\begin{array}{l}\$ 87,000- \\
\$ 180,000\end{array}$ & Full-time & $\begin{array}{l}\text { Four days per } \\
\text { week }\end{array}$ \\
\hline Frank & 25 & 2 & Married & Bachelor & $\begin{array}{l}\text { Software } \\
\text { engineer }\end{array}$ & $\begin{array}{l}\$ 87,000- \\
\$ 180,000\end{array}$ & Full-time & Part-time \\
\hline George & 45 & 1 & Married & Bachelor & IT manager & $\begin{array}{l}\$ 87,000- \\
\$ 180,000\end{array}$ & Full-time & $\begin{array}{l}\text { Four days per } \\
\text { week }\end{array}$ \\
\hline Hamish & 39 & 2 & Married & Bachelor & $\begin{array}{l}\text { Software } \\
\text { engineer }\end{array}$ & $\begin{array}{l}\text { Not } \\
\text { disclosed }\end{array}$ & Full-time & Unemployed \\
\hline
\end{tabular}

\subsection{Data Collection}

In-depth, face-to-face interviews were conducted between July and August 2017 in settings convenient to the participants; typically participants' work places. Interviewing is a powerful method for exploring subjective interpretations that people give to their experiences (Liamputtong \& Ezzy, 1999), "as expressed in their own words" (Taylor \& Bogdan, 1984). The interviews lasted between 25-60 minutes and followed a semi-structured format based on open-ended questions. No strict question order was adhered to when interviewing participants, which allowed for greater flexibility and the ability to pursue leads. The interview questions were developed after a thorough review of relevant literature pertaining to the study topic and addressed topics including, (a) participants' roles and involvement in family food work, (b) perceptions about food provisioning, (c) nutrition and health, and (d) constraining factors preventing involvement in family food work. All interviews were audio-recorded and transcribed verbatim by the researcher. All participants' quotes and summaries of personal histories, opinions and experiences used in this research paper have been identified by pseudonyms so that participants remain anonymous.

\subsection{Data Analysis}

The transcripts were analysed using widely adopted thematic analysis (Guest, et al., 2006) which provides a useful and flexible research tool in identifying, analysing, and reporting patterns or themes within data (Braun \& Clarke, 2006). Atlas.ti, was used to manage and code the interview data, facilitating the analysis of the content of transcripts. Analysis was conducted in accordance with the guidelines offered by Braun and Clarke (2006). The primary author repeatedly read, and familiarised herself with the data, noting patterns that emerged. An appropriate coding development framework, based on the specific questions the research sought to address (Attride-Stirling, 2001), guided the coding process. After discussion with the co-author initial codes were applied to both semantic and latent data content and a codebook developed which provided a descriptive and rigorous method for ensuring data was coded in a consistent and appropriate manner (Guest et al., 2006). All transcripts were systematically coded with both inductive and deductive coding approaches applied (Braun \& Clarke, 2006). Next codes were organised and grouped into overarching themes using a pictorial representation which was useful in sorting and organising codes into themes and concepts (Braun \& Clarke, 2006). At this stage of analysis, collated themes were reviewed and refined several times to ensure they represented patterned responses within the data. The transcripts were carefully reviewed to ensure codes were assigned to appropriate themes. The themes were also assessed to ensure they were coherent, consistent and distinctive and captured important elements about the data in relation to the research question. After consultation with the co-author, the themes were further defined and named. Final analysis of the data was guided by pre-existing patterns present in the literature, the interview semi-structured 
questionnaire and patterned responses within the data. This work was initially written as an essay submitted as part of the requirements of a Master of Public Health.

\subsection{Ethical Considerations}

The study was approved by the Australian National University's Human Ethics Research Committee. All participants gave informed consent about the study and were assured of confidentiality. The participants were encouraged to voice any queries or concerns they had, and advised that their participation was voluntary and that they were able to withdraw their consent at any time before publication without penalty. Furthermore, all participants were allocated a unique study number as they were recruited into the study. This study number was used to identify interview data.

\section{Results}

A small purposive sample of fathers $(n=8)$ aged between 25 and 50 years were recruited from the Canberra region, an area where residents are likely to be better educated, and wealthier than other parts of the country. Table 1 presents the sociodemographic information of the participants involved in the study for the purposes of describing the participants as a group. All participants were or had been married, had tertiary qualifications, worked full-time and were in an upper income level. Most partners worked part-time, with the exception of one who was not currently employed.

\subsection{Gendered Norms}

Participants were asked about their views and attitudes toward contributing to family foodwork. They openly discussed their thoughts and perceptions about fathers' involvement in the domestic space, in particular food provisioning. Whilst many participants acknowledged the persistent gendered role division associated with family food work, all expressed their views on the importance of fathers becoming more actively, if not equally involved in domestic or home/family focused duties.

All participants acknowledged that gender specific practices operate within family environments, with one person explaining that "it's partly historical because society was structured so that men never cooked". They accepted that if it was ever going to really change, men would have to become more conscious of these cultural norms and actively make different choices and priorities, especially with the allocation of time. Some participants were very conscious of their role in the family being more traditional, whereas others, like 44 year old Caleb, actively resisted it and willingly engaged more strongly in challenging traditions. He not only questions his partner's normative role of food provider and his as provider of fun, and active outdoor entertainment, but states the aim that the couple was to do "everything".

“... this is what the stats say as far as I know, that she does more work around the house you know because she's a woman and I don't think that's fair. When the kids were small we both worked part-time... so right from a very early age they were accustomed to me being able to do all those things just as much as Kate (wife pseudonym) could. So they didn't have that expectation of, 'oh you know mum is the one who does the food and dad is the one that, I don't know, takes us riding bikes'. We both tried to be involved in everything." (Caleb)

An aspect of food provisioning in family life where gender roles still appear to dominate is in the 'family favourite' pastime of cooking on the barbecue. Most participants in the study claimed that they tended to be responsible for 'manning the barbeque' when entertaining and feeding family and guests. This practice supports feminist arguments that men continue to dominate public space while women dominate the private space, despite the everincreasing growth in numbers of women in the paid workforce (Australian Bureau of Statistics, 2013; Tanner et al., 2013). However, the use of the word 'manning' by this participant suggests that he and other men are aware of the stereotypes.

Lack of confidence was also used to explain and justify the domestic task division between participants' and their spouses. This has previously been identified in the literature (Namie \& Timmons, 2014). Participants argued that they found feeding their children to be challenging and therefore allowed this activity to be managed by their female partner. It suggests an unfamiliarity with the task.

"Most of the time, a lot of the time...my wife makes his lunches...I feel kind of challenged with what...you know he's so fussy, you don't know whether you're giving him stuff that he's just going to bring home...". (Ethan).

\subsection{Roles and Routines: "It'S Like Clock-Work Our Family"}

Participants discussed their roles in family foodwork activities, with all of them acknowledging their varying involvement in shopping, meal selection and preparation, cooking, feeding and cleaning up. This reflects the increasing body of literature that documents the increasing pressure for fathers to become more involved in 
foodwork (Khandpur, Charles, Blaine, Blake, \& Davison, 2016; Mallan et al., 2014; Petersen, Tanner, \& Fraser, 2014; Tanner et al., 2013). In addition, a commitment to sharing the domestic tasks was frequently expressed by all participants irrespective of their partner's working status. As one person said: "we try to be equal about things and support each other \& parent together". They expressed a conscious decision to create an equal partnership in tasks and responsibilities involved in foodwork. This is supported by the literature stating that fathers are increasingly becoming more involved in family food work activities (Mallan et al., 2014).

Routines were established by more than half of the participants, to facilitate equal contribution and sharing foodwork chores between spouses. Routines ensured fathers' foodwork tasks were attended to, whilst managing other demands such as their paid work commitments. Some participants acknowledged that routines were mostly negotiated between spouses, while others stated "it just happened that way". These routines were applied in the following way: to weekend food preparation, rostered cooking nights, meal selection, and shopping. However, these routine tasks were often referred to in a negative manner, as 'boring' and 'formulaic'.

Conversely, other participants attended to their food work roles in a more 'ad-hoc' manner. For example,

"And other times I'll get a text saying, 'I didn't have a chance to do anything and you know she has to take Sarah (child) to her dance lesson or something so I'll get home and cook. So it's ad hoc but it's negotiated". (Caleb).

\subsubsection{Types of Meals Prepared by Fathers: "There's no Gourmet Meals With Me That's for Sure"}

When fathers were responsible for breakfasts, they were often heavily influenced by their child's preference because they wanted their child to eat. Weekday breakfasts tended to involve quick and simple meals such as cereal and toast while on weekends, fathers tended to put in more effort, choosing to cook meals such as bacon and eggs. The older the child's age, the more likely they were to prepare their breakfasts independently. In Australia, it is common for children to bring a packed lunch from home to school. Most school lunches prepared by fathers involved a sandwich, or wrap, fruit, and often a sweet snack item for morning tea, such as a biscuit. Some fathers prepared hot foods, such as soup, and put it in a thermos.

Dinners varied hugely but predominantly consisted of hot food, such as lasagne, curries, and meat and vegetables. Most participants tended to prepare meals in advance and cook meals in bulk. These meals were then refrigerated or frozen to be consumed at a later date. Fewer fathers reported involving their children in the cooking process. Many fathers commented that on Friday nights the family would go out for dinner or order takeaway as an end of the week 'special' meal. Fathers often gave their children dessert; some every night, to once a week or a few times a month. However, dessert did not involve much food preparation and predominantly consisted of ice-cream, and fruit and yoghurt.

\subsubsection{Tools of the Trade: "Slow Cookers and Freezers"}

To overcome the constraints posed by time scarcity, participants frequently reported that they pre-prepared dinners. During the week, this enabled them to reheat frozen meals that they had prepared in advance. Fathers also utilised slow cookers as this enabled them to prepare and cook future meals while at the same time, participate in other family activities/tasks, such as after school sporting and recreational activities, and homework activities. The idea that dinners, especially week day dinners, had to be 'quick and easy' was frequently reported by the participants. These statements support the idea that time is a critical determinant to fathers' active participation in food provisioning (Jabs \& Devine, 2006; Venn, Banwell, \& Dixon, 2017).

“...sometimes we might be doing like a slow cooked meal and cook extra or have it as a back- up and put it in the freezer" (Frank)

\subsubsection{Catering to Children: "I'll Make an Effort to Cook Stuff I Know the Kids Are Going to Love"}

Cooking meals according to their child's preference was regularly reported. Participants often chose to cook meals their children would enjoy. This was to encourage their child to eat the meal and accommodate the child's mood and expectations. This also supports the argument that time is the scarce commodity (Jabs \& Devine, 2006), as meal times with children are often the pre-cursor to bath and bed-time, and after the child has gone to bed, parents experience their own space and often will actively focus their attention on their own pleasurable pursuits (Russell, Worsley, \& Campbell, 2015).

"I want the evening meal be something that they enjoy and meat and three veg is something I know they both will just lap it up". (Adam)

Another tactic employed by some fathers to encourage their child to eat was the notion of food bribery. This often entailed using dessert or sweets to entice/encourage their children to eat/finish their dinner. It is worth mentioning that these tactics are also employed by mothers (Russell et al., 2015). As Adam told his children, "So, you won't 
get pudding kids, unless you finish your dinner."

Meals were often negotiated between spouses. Regardless of fathers' roles and routines, most participants tended to consult their partners on meal selection, shopping, and task division.

\subsection{Nutrition and Healthiness}

\subsubsection{Perceptions of Healthiness: "it's Definitely Something That'S Healthy.... and Not too Sugary”.}

When discussing their children's diets, fathers often distinguished between "healthy" and "unhealthy" or "good" and "bad" food. Perceptions of healthiness varied amongst participants but ideas centred around home cooking and fresh ingredients. Participants spoke non-specifically about nutrition and health concepts. For example:

"I must do it subconsciously because I don't really think about it. Just that it's healthy". (Benjamin)

They identified what they believed to be 'healthy', which comprised home-made cooking rather than pre-packaged meals, and fresh fruits and vegetables. Foods or ingredients such as sugar, salt, fat, processed items and 'junk food' were frequently referred to as 'bad'. Fathers emphasised the importance of moderating their children's consumption of 'bad' food, with exceptions sometimes made for "special occasions". 'Meat and three veg' was frequently identified as "healthy" family food.

When prompted to articulate their definition of 'healthiness' in relation to food, participants referenced catch phrases. "you know there's other phrases like 'you eat all the colours of the rainbow' all those sorts of things."

These included; balanced diet, colourful food, variety, all the colours of the rainbow, food groups, food pyramid, 'fresh is best', and home cooked. What was unclear was whether these phrases were supported by a deeper nutritional knowledge or an intention to provide healthy food. Indeed, while participants acknowledged the importance of providing healthy and nutritious food for children, they identified barriers to enabling the provisioning of healthy family food. In the following quotation Benjamin, attributes problems to other "people" rather than himself.

"but yeah, people's laziness that make children unhealthy pretty much. 'Coz kids don't really have a choice do they?" (Benjamin)

3.3.2 Nutrition Information “Talking to People, and Yeah Reading Other People'S Papers or Whatever They'Ve Written and Then Deciphering for Myself What I Do and Don'T Like."

An important element of this study, was gaining an understanding of how much attention fathers paid to nutrition. It appears that they gain information on the topic in an ad hoc manner. Nutritional resources, when accessed, often came from media outlets including newspaper articles, television and radio programs, and cook books.

"No I think a lot of my ideas about how to get them to think about food has come from watching the hysteria from the healthy eating articles like paleo. I think there's hysteria in all of it and so what I've tried to do is read a little bit of that stuff, not much, and try and work out what the actual essence of it and you know where the truth probably is and then apply that." (Daniel)

Participants identified another source of nutritional information which was distributed through the schools. School initiatives included 'fruit break' or 'the crunch and sip', encouraging parents to ensure their child had water and a piece of fruit or vegetable every day. Certain schools also offered nutritional education on 'healthy' food and canteens had implemented a coloured food system, where: "green is always food and orange sort of sometimes food. Just to give them an idea of what and the parents too I guess..." (Daniel)

In addition, familial heritage and personal experiences also influenced nutritional understanding and practices. Culture and family upbringing is often associated with food preferences (Smith, Dunton, Pinard, \& Yaroch, 2016).

"but also you know we eat a lot like how I ate as a kid. So more like that." (Daniel)

All the participants acknowledged that they did not specifically seek nutritional advice for their children. Participants interested in nutrition pertaining to adult physiology, applied similar concepts when providing food for their own children. They acknowledged they had not received any specific nutritional advice for their children since they were born.

"so we haven't gone out of our way to look for specific nutritional guidance for children but I think it comes into our thinking." (Adam).

"I don't know I must do it subconsciously because I don't really think about it - just that its healthy." (Benjamin) 


\subsubsection{Influences on Food Selection: "I Will Get the 4 Star Mince".}

Marketing strategies had a role in influencing participants' choice of nutritional products. For example, Daniel explains why he chooses a particular type of mince.

"I think the three star mince looks like rubbish and the five-star mince I think is a wank [unnecessary carry on], so I pick the middle one." (Daniel)

This finding is well supported by large-scale literature reviews that shows exposure to food marketing affects and shapes children's food preferences, short- and long-term dietary consumption, and purchase requests directed to parents (Chernin, 2008). Children are understood to be a major driver of family food purchases through the strength of pester power.

Most participants said they used nutritional labelling on packaged items. They were more likely to read the nutritional labels if they were comparing specific products or if their children had food allergies. Fathers that were experienced in comparing the same products were aware of specific ingredients/additives to look for, along with the percentage of these ingredients or additives in the product. Fathers whose children suffer various allergies initiated by specific additives found in some food groups, such as gluten and cashews were particularly familiar with labelling. A few participants discussed cost as a potential barrier for preventing the provisioning of healthy food. "I do the shopping so I probably would go by default for the cheaper options than the more expensive options." In general, products labelled as health foods are often more expensive than similar ones that do not claim health food status.

\subsection{Barriers to Fathers' Involvement in Food Work}

Fathers' said that their commitments to work, including time scarcity and cost, were the main reasons that they did not have greater involvement. As one father said: "I don't really have any input of what they eat in the afternoon because you know I'm still working." They discussed their choices and priorities with most regularly prioritising paid working commitments over their family food work responsibilities. Their food work duties tended to be flexible to facilitate paid working commitments and priorities. For example:

"So I guess that's what gets in the way, its commitments, it would be...commitments that I have.

I mean they're things like the sporting commitments, might be going out and doing...some exercise, then it might be taking our child to a playdate with other kids, you know..there might be umm...catching up with other family, those kinds of usual things that just mean that you can't be chained to a kitchen all the time". (Ethan)

Some participants either worked from home or had flexible paid working arrangements to accommodate family commitments. As one participant noted,

"because [of] the fact that I'm working from home allows me to spend a lot of time with my family, but that means that I need to complement my work somehow and that tends to be at evenings", and his wife tends to do the cleaning up after dinner.

Fathers often deferred cleaning up responsibilities to their spouses to accommodate paid working commitments. Participants with spouses not currently working or working part-time hours tended to defer their food work roles and responsibilities to their spouse and may be supported by the theory that partners allocate domestic work to the lower income earner (Beagan, Chapman, D'Sylva, \& Bassett, 2008). Hamish said: "Naturally, because I work and my wife doesn't at the moment, I tend to work more and she tends to take care of the kids more." The use of the word "naturally" signals the normative assumptions here.

Time scarcity was a common theme discussed by all participants, particularly as it was limited by their other commitments. So I've got an hour and half really to feed, homework and all that sort of stuff". Many fathers stated that they felt 'overwhelmed' by all their food work responsibilities, such as cooking, feeding, and cleaning up, within given timeframes. Meals were prepared and cooked on the weekends and then frozen for use throughout the up-coming week to accommodate time scarcity throughout the week. Shopping was regularly done on the weekends due to participants having more 'free time'. Lack of time was often associated with working commitments (Australian Bureau of Statistics, 2016).

\section{Discussion}

Based on this small sample, our results show that these fathers are taking an active role in family food work, such as food selection, shopping, preparing food, cooking and cleaning up, possibly more so than men in the past. Over recent decades in Australia, men have increased their average time spent on household work by an hour and 25 minutes to 18 hours and 20 minutes a week (Australian Bureau of Statistics, 2013). Our participants were interested 
in sharing the food work responsibilities, with all voicing the importance of sharing domestic tasks within their own families. Their comparatively younger age suggests that a generational shift in attitude is taking place.

However, despite their expressed commitment to an equal division of food work duties between partners, most fathers seemed to need to 'step up' or fill the role when their partner was unable to. This was largely due to their lack of confidence in the food work space, particularly in cooking food their children would eat, and their prioritisation of other commitments such as paid work. Fathers appeared to 'unconsciously' accept mothers' expertise and capability in cooking for children which promulgated the maintenance of traditional gendered roles in the family. Furthermore, participants suggest that they deferred overall responsibility for food work duties to their spouses. However, the partners of the participants were not interviewed and therefore, we cannot definitely say where the ultimate responsibility lay.

Participants in this study acknowledged the need for change, with some going as far as negotiating flexible work arrangements, and establishing routines for shared cooking responsibilities. Employment patterns for both men and women have changed over the last few decades with the proportion of women employed significantly increasing (Australian Bureau of Statistics, 2006). In 2018, women's workforce participation rate was $60.4 \%$ in Australia (Australian Government, 2018). Despite this increase of women in the workforce, the responsibility for decision-making and simply being conscious of the immediate everyday needs of their family still seems to form a major part of the woman's role (Beagan et al., 2008; Tanner et al., 2013). Existing research on the domestic division of labour shows women experience a disproportionate responsibility for food work tasks, despite their increasing involvement in paid work (Beagan et al., 2008; Yeung, Sandberg, Davis-Kean, \& Hofferth, 2001). The 2016 census figures support this consistent finding and shows that the average woman in Australia spends between five to 14 hours a week on domestic work compared to men spending less than five hours per week (Australian Bureau of Statistics, 2016).

Time scarcity, usually related to work commitments, occurs when people feel they do not have enough time to do all they want or need to in a day. It was proffered as the main reason for impeding participants' involvement in food work activities. Most fathers worked at least 40 hours per week, and their partners were mostly employed in a part-time capacity, ranging from 20 to 32 hours per week. Whilst all participants mentioned their commitment to sharing food work responsibilities, female partners worked less hours and shouldered more of the domestic unpaid work responsibilities as is common in Australia (Maher, Fraser, \& Wright, 2010; Australian Bureau of Statistics, 2016). None of the participants implicitly stated they perceived themselves as the main 'breadwinner' of the family and they were committed to sharing food work and other family tasks.

Some participants had negotiated flexible working arrangements, such as working from home, to enable them to be more involved in family food work activities, including meal selection, shopping, and cooking. Whilst working from home permitted fathers greater availability to attend and assist in these tasks, the responsibility and decisionmaking associated with family food provisioning often fitted around their working commitments. Flexible working conditions often means that salaried workers spend nights and weekends working from home to meet deadlines and demands (Dixon, Banwell, Strazdins, Corr, \& Burgess, submitted). Nearly all participants felt pressed for time when it came to attending family food work. This is consistent with figures from the Australian Bureau of Statistics claiming that $46 \%$ of Australian men who provided care felt rushed for time (Australian Bureau of Statistics, 2016). Preparing and cooking dinner was the meal-time where most participants felt time pressured. Fathers referred to the few hours they had, to ensure their child was fed, bathed and ready for bed, and for older children that their homework was completed. The idea that dinners, especially week day dinners, had to be 'quick and easy' was frequently reported by the participants. These statements support the idea that time is a critical determinant to fathers active participation in food provisioning (Jabs \& Devine, 2006; Venn et al., 2017). To balance family responsibilities and paid working requirements, fathers used a range of methods when preparing family meals that reorganised time. These included: cooking meals in advance; freezing and then reheating these meals; and using slow cookers. In this sense, this use of technologies such as freezers, micro-waves and home cookers are seen to, "help to redistribute time and labour and alleviate some of the pressures of modern life" (Shove \& Southerton, 2000 p.315).

Participants were aware of a general definition of 'healthiness', when they articulated their considerations and perceptions on healthy family food provisioning. The use of nutritional slogans and catch phrases, indicated that health strategies employed by health researchers, governments and the food industry are being received by fathers (Adams \& Geuens, 2007). They readily distinguished between 'healthy' and 'unhealthy' or 'good' and 'bad' food. Home-made cooking and fresh ingredients were perceived to be healthy, whilst foods and ingredients such as sugar, salt, fat, processed items and 'junk food' were frequently referred to as 'bad'. Venn and colleagues argue the food 
practice in Australia, particularly the increase in commercially pre-prepared and ultra-processed foods, has changed rapidly due to interrelating factors such as a reduction in time spent in food preparation and cooking, women's labour force participation the rise of the food service industry and increase in money to 'eat out' (Venn et al., 2017). However interestingly, participants discussed eating out only on "special occasions", and using processed and packaged products infrequently. This however, contradicts statements about frequently eating out or using takeaway food on many Friday nights. During the week, fathers tended to provide meals 'from scratch' using fresh ingredients, or pre-prepared home cooked meals. They expressed their commitment to healthy food by preparing home cooked meals for their family. In this manner, fathers sought to present themselves as responsible paternal citizens, shown by their attentiveness to information about weight and diet and by efforts to inform themselves about the "healthy" foods they should feed their families. As we did not interview the participants' partners, we cannot say if mothers provide "healthier" food than fathers or are more nutritionally informed. Socio-cultural values around food provisioning are associated with factors such as income and education (Venn et al., 2018). These participants are well educated and remunerated, and as white collar workers on a salary they were like to have access to flexible working hours - all factors that may buttress the provision of home-cooked healthy meals.

Most participants had not specifically received or accessed child nutritional information since their child was born, although they had casually absorbed information through their daily activities. There were two exceptions: father of children with food allergies and intolerances sought out specific nutritional information. This indicates that these fathers may be more actively engaged in identifying not just healthy foods but foods that cause detrimental health impacts on their children. As such, the predominant incentive is for the father to actively select, prepare and cook foods that will not obviously harm their child, as opposed to providing healthy food.

If participants obtained nutritional information it often came from media outlets including newspaper articles, television and radio programs, and cook books. However, participants 'cherry picked' the specific health content that either, they were comfortable working with or that they understood more readily or they applied concepts from adult nutrition to children. Children's food preferences were a predominant consideration by all fathers when deciding what meals to prepare. Food preferences play a huge role in determining children's food intake and are a common strategy used by parents to encourage feeding (Russell et al., 2015; Vaughn et al., 2016). Understanding how fathers, and more generally parents, can influence their child's food preference is important, to encourage parents to improve their child's feeding practices and overall diet quality (Vollmer \& Baietto, 2017). Children's preferences may influence the entire family's diet (Dixon \& Banwell, 2004; Coveney, 2006).

In Australia, as in many other Western countries, childhood obesity has become a focal topic in public health discourse (Banwell, Broom, Davies, \& Dixon, 2012; Maher et al., 2010; Petersen et al., 2014). Despite efforts by government and peak health bodies to combat the prevalence of obesity, particularly among children, the burden of this remains largely unchanged (Venn et al., 2017). Whilst individuals will always have responsibility in this space, there are also complex social factors (Maher et al., 2010), including work family balance, a dynamic labour market, changing cultural and gendered norms that should be considered. Existing research and policy initiatives have predominantly focused on mothers' role in managing children's food intake rather than parents in general (Maher et al., 2010). Policy makers and researchers need to be aware that men are beginning to play a more active role in food work, although we don't yet know how prevalent this is and whether it is confined to particular groups. There may be a need to develop and implement strategies to encourage fathers to access appropriate health and nutritional resources for their children. Whilst this research has focused on fathers as food providers, it has highlighted that women are still disadvantaged by the amount of unpaid housework they do. Women's paid working hours have increased in the last few decades, a change that has not generally been reciprocated by changes in men's care-giving or unpaid domestic work (Maher et al., 2010). It raises the question how can parents and their children be supported in this dual income earner environment? Future research may benefit by exploring more widely who 'contemporary fathers' are in terms of their socio-economic status and their cultural values, and their contribution to family food provisioning?

\section{Limitations}

Although this study's sample size was small, the interviews were purposefully designed to elicit in-depth, rich, informative data, to provide insight into an under-researched area. This study indicates a need for a future largerscaled study that overcomes the limitations identified here. Ideally, this study should be duplicated among men from a range of socio-economic, geographically and ethnically diverse backgrounds to explore barriers related to work, time and financial resources among these groups. It would also be valuable to include mothers and children as our study indicates that family food work is negotiated within the family. Given the primary researcher is a 
woman, this may have influenced the male participants responses in this gender sensitive discourse.

\section{Conclusion}

This small study highlights a number of important findings that have implications for children's weight and health. Our participants were a well-educated, well-resourced group of fathers who articulated a willingness to be more involved in family food work than perhaps men of earlier generations were. This research suggests men are moving into food provisioning space while research and policy remains focussed on gendered norms of the $20^{\text {th }}$ century. Larger studies with more diverse groups of men, would be useful to further understand 21 st century fathering, and its potential health impacts. Although gendered family norms are in transition, our findings suggest that women still take the lead concerning food work; decision-making, its production and how and where it is consumed (Beagan et al., 2008; Petersen et al., 2014). Despite the plethora of information about healthy food practices for children, the intended recipients of this advice are women and it seems fathers do not actively investigate or access these resources. Therefore, further research could focus on men's nutritional knowledge and practices around feeding children with the aim of developing tools and initiatives that would encourage fathers to be more aware of their impact on children's health. It also raises the question of who has the responsibility to orchestrate and implement these initiatives to encourage fathers to take on more active participation in accessing nutritional and health family resources?

\section{Competing Interests Statement}

The authors declare that there are no competing or potential conflicts of interest.

\section{References}

Australian Bureau of Statistics. (2006). 4102.0 - Australian Social Trends, 2006. Retrieved from http://www.abs.gov.au/AUSSTATS/abs@.nsf/bb8db737e2af84b8ca2571780015701e/858badad39afb98dca2 571b000153d73!OpenDocument

Australian Bureau of Statistics. (2013). 4102.0 - Australian Social Trends, March 2009. Retrieved from http://www.abs.gov.au/AUSSTATS/abs@.nsf/Lookup/4102.0Main+Features40March 2009

Australian Bureau of Statistics. (2016). 2024.0-Census of population and housing: Australia revealed, 2016. Retrieved from www.abs.gov.au/ausstats/abs@.nsf/mf/2024.0

Australian Government. (2018) Gender workplace statistics at a glance. Retrieved from https://www.wgea.gov.au/sites/default/files/Stats_at_a_Glance.pdf

Adams, L., \& Geuens, M. (2007). Healthy or Unhealthy Slogans: That's the Question. Journal of Health Communication, 12(2), 173-185. https://doi.org/10.1080/10810730601152755

Attride-Stirling, J. (2001). Thematic networks: an analytic tool for qualitative research. Qualitative Research, 1(3), 385-405. https://doi.org/10.1177/146879410100100307

Banwell, C., Broom, D., Davies, A., \& Dixon, J. (2012). Weight of Modernity. Springer.

Bava, C. M., Jaeger, S. R., \& Park, J. (2008). Constraints upon food provisioning practices in 'busy' women's lives: Trade-offs which demand convenience. Appetite, 50(2), 486-498. https://doi.org/10.1016/j.appet.2007.10.005

Beagan, B., Chapman, G. E., D'Sylva, A., \& Bassett, B. R. (2008). 'It's Just Easier for Me to Do It': Rationalizing the Family Division of Foodwork. Sociology, 42(4), 653-671. https://doi.org/10.1177/0038038508091621

Braun, V., \& Clarke, V. (2006). Using thematic analysis in psychology. Qualitative Research in Psychology, 3(2), 77-101. https://doi.org/10.1191/1478088706qp063oa

Chernin, A. (2008). The Effects of Food Marketing on Children's Preferences: Testing the Moderating Roles of Age and Gender. The Annals of the American Academy of Political and Social Science, 615(1), 102-118. https://doi.org/10.1177/0002716207308952

Coveney, J. (2006) Food, Morals and Meanings. Routledge.

Dixon, J., Banwell, C., Strazdins, L., Corr, L., \& Burgess, J. (2019). Flexible labour markets, compromised job control and preventive health practices' Human Relations (subm 17/1/19).

Dixon, J., \& Banwell, C., (2004). Heading the table; parenting and the junior consumer. British Food Journal, 106(3), 181-193.

Fouts, H. N., \& Brookshire, R. A. (2009). Who feeds children? A child's-eye-view of caregiver feeding patterns among the Aka foragers in Congo. Soc Sci Med, 69(2), 285-292. 
https://doi.org/10.1016/j.socscimed.2009.05.016

Gilligan, C. (1982). In a different voice: Psychological theory and women's development. Cambridge, Mass: Harvard University Press.

Australian Government, (2016). Gender workplace statistics at a glance. Retrieved from https://www.wgea.gov.au/sites/default/files/Stats_at_a_Glance.pdf

Guest, G., Bunce, A., Johnson, L., (2006). How many interviews are enough? An experiment with data saturation and variability. Field Methods, 18(1) 59-82.

Jabs, J., \& Devine, C. M. (2006). Time scarcity and food choices: An overview. Appetite, 47(2), 196-204. https://doi.org/10.1016/j.appet.2006.02.014

Khandpur, N., Blaine, R. E., Fisher, J. O., \& Davison, K. K. (2014). Fathers' child feeding practices: a review of the evidence. Appetite, 78, 110-121. https://doi.org/10.1016/j.appet.2014.03.015

Khandpur, N., Charles, J., Blaine, R. E., Blake, C., \& Davison, K. (2016). Diversity in fathers' food parenting practices: A qualitative exploration within a heterogeneous sample. Appetite, 101, 134-145. https://doi.org/10.1016/j.appet.2016.02.161

Khandpur, N., Charles, J., \& Davison, K. K. (2016). Fathers' Perspectives on Coparenting in the Context of Child Feeding. Childhood Obesity, 12(6), 455-462. https://doi.org/10.1089/chi.2016.0118

Liamputtong, P., \& Ezzy, D. (1999). Qualitative research methods: a health focus. South Melbourne, Vic: Oxford University Press.

Maher, J., Fraser, S., \& Wright, J. (2010). Framing the mother: childhood obesity, maternal responsibility and care. Journal of Gender Studies, 19(3), 233-247. https://doi.org/10.1080/09589231003696037

Mallan, K. M. (2013). The Role of Fathers in Feeding Children. Pediatrics for Parents, 29(5/6), 28.

Mallan, K. M., Daniels, L. A., Nothard, M., Nicholson, J. M., Wilson, A., Cameron, C. M., . . Thorpe, K. (2014). Dads at the dinner table. A cross-sectional study of Australian fathers' child feeding perceptions and practices. Appetite, 73, 40-44. https://doi.org/10.1016/j.appet.2013.10.006

Mallan, K. M., Nothard, M., Thorpe, K., Nicholson, J. M., Wilson, A., Scuffham, P. A., \& Daniels, L. A. (2014). The role of fathers in child feeding: perceived responsibility and predictors of participation. Child Care Health Dev, 40(5), 715-722. https://doi.org/10.1111/cch.12088

Namie, J., \& Timmons, H. (2014). Faith and Feeding the Family: Latter-day Saint Fathers and Foodwork. Food and Foodways, 22(4), 247-267. https://doi.org/10.1080/07409710.2014.964588

Owen, J., Metcalfe, A., Dryden, C., \& Shipton, G. (2010). 'If they don't eat it, it's not a proper meal': Images of risk and choice in fathers' accounts of family food practices. Health, Risk \& Society, 12(4), 395-406. https://doi.org/10.1080/13698571003793213

Petersen, A., Tanner, C., \& Fraser, S. (2014). Practicing Food Anxiety: Making Australian Mothers Responsible for Their Families' Dietary Decisions. Food and Foodways, 22(3), 175-197. https://doi.org/10.1080/07409710.2014.935671

Ponelis, S. R. (2015). Using Interpretive Qualitative Case Studies for Exploratory Research in Doctoral Studies: A Case of Information Systems Research in Small and Medium Enterprises. International Journal of Doctoral Studies, 10, 535-550.

Russell, C. G., Haszard, J. J., Taylor, R. W., Heath, A. M., Taylor, B., \& Campbell, K. J. (2018). Parental feeding practices associated with children's eating and weight: What are parents of toddlers and preschool children doing? Appetite 128, 120-128. https://doi.org/10.1016/j.appet.2018.05.145

Russell, C. G., Worsley, A., \& Campbell, K. J. (2015). Strategies used by parents to influence their children's food preferences. Appetite, 90(Supplement C), 123-130. https://doi.org/10.1016/j.appet.2015.02.038

Schubert, E. (2009). Diet and domestic life in $21^{\text {st }}$ century Australia: An Exploration of Time an Convenience in Family Food Provisioning. PhD Thesis, School of Population Health, The University of Queensland.

Shove, E., \& Southerton, D. (2000) Defrosting the freezer: from novelty to convenience. A narrative of Normalization. Journal of Material Culture, 5(3), 301-319.

Slater, J., Sevenhuysen, G., Edginton, B., \& O'Neil, J. (2012). 'Trying to make it all come together': structuration and employed mothers' experience of family food provisioning in Canada. Health Promotion International, 
27(3), 405-415. https://doi.org/10.1093/heapro/dar037

Smith, T. M., Dunton, G. F., Pinard, C. A., \& Yaroch, A. L. (2016). Factors influencing food preparation behaviours: findings from focus groups with Mexican-American mothers in southern California. Public Health Nutrition, 19(5), 841-810. https://doi.org/10.1017/S1368980015001949

Stanford Children's Health. (2017). Nutrition-school children. Retrieved from http://www.stanfordchildrens.org/en/topic/default?id=school-aged-child-nutrition--90-P02280

Tanner, C., Petersen, A., \& Fraser, S. (2013). Food, fat and family: Thinking fathers through mothers' words. Women's Studies International Forum, 44, 209. https://doi.org/10.1016/j.wsif.2013.01.017

Taylor, S. J., \& Bogdan, R. (1984). Introduction to qualitative research methods: the search for meanings (2nd ed.). New York: Wiley.

Vaughn, A. E., Ward, D. S., Fisher, J. O., Faith, M. S., Hughes, S. O., Kremers, S. P. J., . . Power, T. G. (2016). Fundamental constructs in food parenting practices: a content map to guide future research. Nutrition Reviews, 74(2), 98-117. https://doi.org/10.1093/nutrit/nuv061

Venn, D., Banwell, C., Dixon, J., \& Strazdins, L. (2018). Social determinants of household food expenditure in Australia: the role of education, income, geography and time. Public Health Nutr, 21(5), 902-911 https://doi.org/10.1017/S1368980017003342

Venn, D., Banwell, C., \& Dixon, J. (2017). Australia's evolving food practices: A risky mix of continuity and change. Public Health Nutr, 20(14), 2549. https://doi.org/10.1017/S136898001600255X

Vollmer, R. L., Adamsons, K., Foster, J. S., \& Mobley, A. R. (2015). Investigating Relationships Between Paternal Perception of the Role of the Father and Paternal Feeding Practices. Journal of Child and Family Studies, 24(12), 3734-3741. https://doi.org/10.1007/s10826-015-0181-z

Vollmer, R. L., \& Baietto, J. (2017). Practices and preferences: Exploring the relationships between food-related parenting practices and child food preferences for high fat and/or sugar foods, fruits, and vegetables. Appetite, 113(Supplement C), 134-140. https://doi.org/10.1016/j.appet.2017.02.019

Yeung, W. J., Sandberg, J. F., Davis-Kean, P. E., \& Hofferth, S. L. (2001). Children's Time with Fathers in Intact Families. Journal of Marriage and Family, 63(1), 136-154. https://doi.org/10.1111/j.17413737.2001.00136.x

\section{Copyrights}

Copyright for this article is retained by the author(s), with first publication rights granted to the journal.

This is an open-access article distributed under the terms and conditions of the Creative Commons Attribution license (http://creativecommons.org/licenses/by/4.0/). 